\title{
Aus dem Vorwort zur elften Auflage
}

Die wissenschaftliche Medizin verwendet so viel Kunstansdräcke und Fremdwörter, daB es auch dem Belesenen unmöglich ist, sie im Gedăchtnis zn bewahren. Das gilt noch besonders von den zahlreichen Krankheiten, Zeichen usw., die mit dem Eigennsmen des Entdeckers benannt werden.

Dies Băchlein stellt deshalb die gebrauchlichen Fremdworter mit kurzer Angabe der Ableitung und der Bedentung und die wichtigsten Kunstausdrticke ans den alten und ans den neuen Sprachen zusammen. Dabei ist tuberall mehr Wert daranf gelegt worden, die Worter zu bringen, die dem Leser begegnen, als Bezeichnungen zu sammeln, die einzig ihr Frfinder und nie ein anderer verwendet hat. Durch knappe Fassung der Errklarungen und durch Verzicht anf zwecklose Anfthrung anatomischer, zoologischer usw. Namen konnte bei geringem Umfang eine sehr grobe Zahl von wichtigen Stichworten behandelt werden.

Wiesbaden, Oktober 1922

\section{Der Verfagser.}

\section{Vorwort zur dreizehnten und vierzehnten Auflage}

Durch den inzwischen erfolgten Tod des Kollegen Dornblüth war die Bearbeitung der vorliegenden Auflage durch einen anderen erforderlich. Wenn nun auch wesentlich im Sinne des Toten weitergearbeitet werden soll, so ergab sich doch die Notwendigkeit eingreifender Ānderungen: Es muBte den neueren serologischen und allgemein biochemischen Fragen ein weiterer Raum als seither zugebilligt werden. Dadurch hätte das Büchlein seinen Umfang wesentlich überschritten und 
den Charakter der möglichsten Kürze eingebüBt. So beschlossen denn Verlag und Verfasser die französischen und englischen Wörter fallen zu lassen, bzw. sie nur da zu halten, wo der fremde erste Autor eine typische, später in den allgemeinen Sprachgebrauch übergegangene Bezeichnung gewählt hatte. (Es hatten doch anch diese fremdsprachlichen Worte nur für einen recht kleinen Teil des Leserkreises Gebranchswert und gerade diesem fehlte dann doch noch beim dentschen Stichwort die tbersetzung in die fremde Sprache.) So wurde denn reichlich Raum fur eingehendere Sachbearbeitung gewonnen. - Es wurde z. B. ermöglicht, ohne wesentliche Zunahme des Buchumfangs, die fräher nicht vorhandenen Harn-, Blutreaktionen nsw., ferner bei den Infektionskrankheiten kurz den typischen Verlanf, die bakteriologische und serologische Frage und ebenfalls kurz die Differentialdiagnose $\mathrm{zu}$ behandeln.

Möge denn das Büchlein in der neuen Fassung gleich beliebt sein, wie in der alten.

Möge auch der Leser mitarbeiten and Versäumnisse nachholen helfen.

Berlin, August 1927.

Dr. Bannwarth. 